\title{
Adaptability of Powdered Activated Carbon Production from Ground Catering Waste Pyrolysis Coke
}

\author{
G. NAGY1 ${ }^{1}$ A. SIMON ${ }^{2}$, R. GÉBER ${ }^{3}$, Á. RÁCZ ${ }^{4}$ \\ ${ }^{1}$ University of Miskolc, Faculty of Materials Science and Engineering, Institute of Energy and Quality, \\ nagy.gabi@uni-miskolc.hu \\ ${ }^{2}$ University of Miskolc, Faculty of Materials Science and Engineering, Institute of Ceramic and Polymer \\ Engineering, simon.andrea@uni-miskolc.hu \\ ${ }^{3}$ University of Miskolc, Faculty of Materials Science and Engineering, Institute of Ceramic and Polymer \\ Engineering, femgeber@uni-miskolc.hu \\ 4University of Miskolc, Faculty of Earth Science and Engineering, Institute of Raw Material Preparation and \\ Environmental Processing, adam.racz@uni-miskolc.hu
}

Abstract. Three mixture of catering waste was pyrolyzed at 650, 725 and $900{ }^{\circ} \mathrm{C}$ and the solid residue (coke) was examined for powdered activated carbon production. For this, the carbon content, iodine number, particle size distribution and scanning electron microscopic images were analysed. Based on the carbon content, these cokes are suitable for activated carbon production, which were 60-85 wt.\% (depending on the base material and pyrolysis temperature). The studied cokes showed slightly porous structure with smooth surfaces. Because of this, the iodine number was mostly small (13-30). Based on the grinding experiments, 10 minutes of grinding was found to be optimal. After this grinding time, the reached iodine number of powdered activated carbon was 350-610.

Keywords: activated carbon, catering waste, pyrolysis, pyrolysis coke

\section{Introduction}

Carbonaceous material produced from raw materials under high temperature reactions that have high internal surface area and highly developed porous structure is referred to as activated carbon (AC) [1]. AC can be produced by such thermochemical conversion methods of carbonaceous feedstock as pyrolysis or carbonization. In many cases, the required porous structure cannot be achieved with these processes alone, therefore, different types of activation methods can be used. These methods may be physical or chemical processes. During physical activation, the first step is carbonization to eliminate the volatile matters from the base material. The next step is the activation which usually occurs above $800{ }^{\circ} \mathrm{C}$ in steam, nitrogen, argon or carbon dioxide media. For chemical activation, first, the base material is impregned by a dehydrating chemical agent and next, the chemical activation and carbonization take place in one step at lower temperature than during physical activation [2].

AC can be in powdered, granular or extruded form for different applications. During our experiments, powdered activated carbon (PAC) was made by grinding after the pyrolysis of the raw material. According to the European Council [3], "PAC is defined as consisting of at least $90 \%$ by weight 
(weight\%) of particles with a size less than $0.5 \mathrm{~mm}$ " and the requirement of the ASTM D5158 standard [4] is that the PAC particles pass through an 80 mesh sieve (below $0.177 \mathrm{~mm}$ ). PAC can be used for various purposes, for example mercury vapour capture [5], organic micropollutants removal during wastewater treatment [6], odour removal of drinking water [7] or dioxin adsorption in flue gas [8].

AC can be produced from any carbonaceous material (fossil, waste or renewable), therefore food waste can also be used. According to the latest study carried out in the EU member states, [9] on average, $11.6 \%$ of the food produced in the EU becomes waste. In case of the USA [10], the ratio rises to approximately $31 \%$. According to a 2012 study [11], 56\% of the food waste is catering waste, which according to the Commission Regulation (EU) No 142/2011 means "all waste food, including used cooking oil originating in restaurants, catering facilities and kitchens, including central kitchens and household kitchens" [12].

During pyrolysis, the carbonaceous material can be transformed into gaseous (pyrolysis gas or synthesis gas) and liquid products (pyrolysis oil), and solid material (pyrolysis coke) with high carbon content remains in the reactor. The gas can be used as chemical raw material beside the energetic application, the liquid is suitable for combustion or different chemicals can be extracted from it. The main users of the solid residue are the metallurgical and energy industry, but it has high importance as a soil conditioner or activated carbon [13]. Pyrolysis can be a good way to utilize food waste, including catering waste too [14]. The literature of this topic is minimal. Only one significant publication-deals with activated carbon production. Krithiga et al. [15] used cooked rice as the base material of activated carbon production via chemical activation. The BET specific surface area of the produced activated carbon were 306.83 and $539.78 \mathrm{~m}^{2} / \mathrm{g}$, depending on the activation agent. Furthermore, when producing activated carbon from food waste, most researches focus on using base materials like agricultural by-products [16] or wastes generated during food production, for example potato peels [17], orange peels [18], olive stones [19], etc.

During our experiments, catering waste was modelled by three mixture. One of the mixtures contained foods of plant origin, the other one contained foods of animal origin and the last one consisted of foods with plant and animal origin. These were pyrolyzed at three temperatures: 650,725 and $900{ }^{\circ} \mathrm{C}$. These temperatures are commonly used for the pyrolysis of biomass [20]. After the pyrolysis, the change of specific surface area (based on iodine number) of pyrolysis cokes was measured as a function of the type of base material and the pyrolysis temperature. In case of the mixture of animal and plant origin food, the effect of coke grinding time was examined, as well.

\section{Materials and methods}

Canteen waste was modelled with three type of food mixture, which can be found in a regular Hungarian canteen. A mixture of vegetable food (1:1 mass ratio of cooked rice and French fries), a mixture of food of animal origin (1:1 mass ratio of breaded pork and roast chicken breasts) and a mixture, which contains food with animal and plant origin (1:1 mass ratio of cooked rice and breaded pork) were prepared. The examined properties of the mixtures are summarized in Table 1 . 
The lab-scale pyrolyzing system can be seen in Figure 1. As the furnace is turned on, the reactor is heated to 650,725 or $900{ }^{\circ} \mathrm{C}$ with $20^{\circ} \mathrm{C} / \mathrm{min}$ heating rate, then the holding time lasts for 70 minutes which is necessary for the gas production to decrease below $1 \mathrm{l} / \mathrm{h}$.

\begin{tabular}{|c|c|c|c|c|c|}
\hline & \multicolumn{2}{|c|}{ Parameter } & $\begin{array}{c}\text { Cooked rice and French } \\
\text { fries in 1:1 mass ratio } \\
\text { (CRFF) }\end{array}$ & $\begin{array}{c}\text { Cooked rice and } \\
\text { breaded pork in 1:1 } \\
\text { mass ratio (CRBP) }\end{array}$ & $\begin{array}{c}\text { Breaded pork and roast } \\
\text { chicken breasts in 1:1 } \\
\text { mass ratio (BPRC) }\end{array}$ \\
\hline \multirow{6}{*}{ 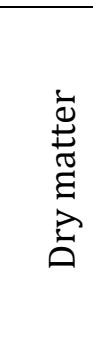 } & Nitrogen & \multirow{6}{*}{ wt. $\%$} & 1.78 & 9.87 & 11.57 \\
\hline & Carbon & & 49.86 & 53.84 & 54.84 \\
\hline & Hydrogen & & 6.93 & 7.51 & 7.49 \\
\hline & Sulphur & & 1.06 & 1.37 & 0.77 \\
\hline & Oxygen & & 38.50 & 24.89 & 22.14 \\
\hline & Ash & & 1.87 & 2.52 & 3.20 \\
\hline \multicolumn{2}{|c|}{$\begin{array}{l}\text { Moisture content } \\
\text { of original matter }\end{array}$} & wt.\% & 41.29 & 46.88 & 51.10 \\
\hline
\end{tabular}

Table 1. Ultimate and proximate analysis of base materials.
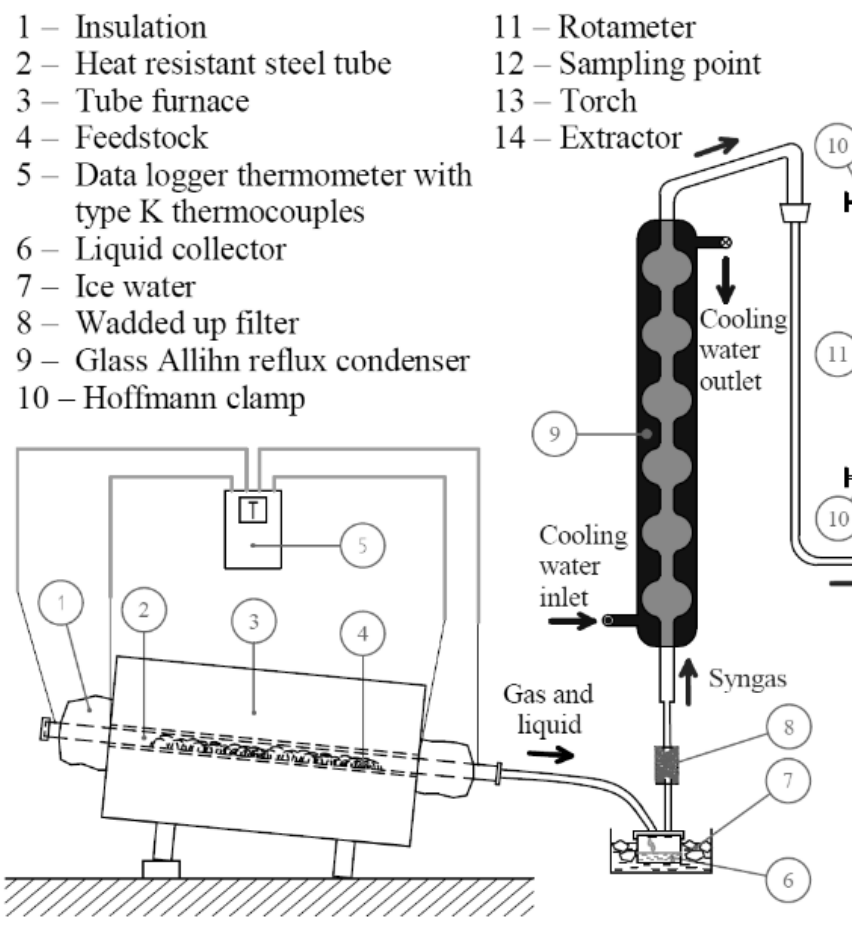

Figure 1. Schematic illustration of the lab-scale pyrolyzing system.

14 - Extractor
11 - Rotameter

12 - Sampling point

13 - Torch

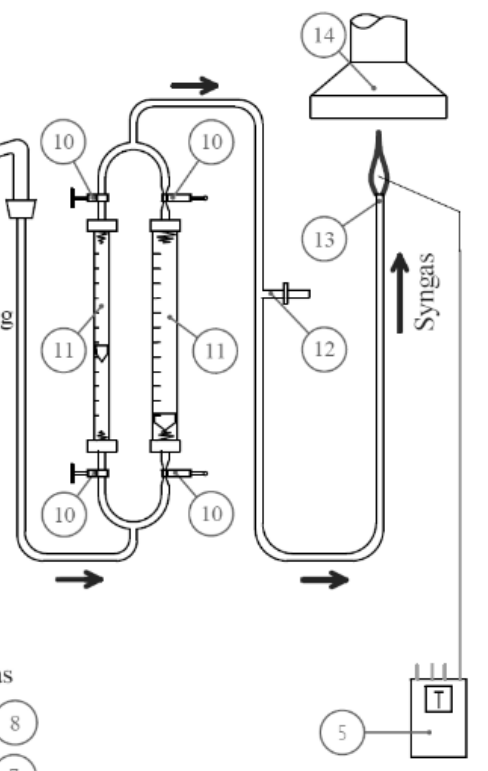

The coke was crushed in a mortar to reduce the particle size under $1 \mathrm{~mm}$, then milled for 5, 10 and 15 minutes with 300 revolutions per minute in a Fritsch Pulverisette 6 planetary ball mill. The carbon content of the samples was determined with a Carlo Erba EA 1108 elemental analyzer. The analysis of specific surface area was carried out according to "D 4607 - 94: Standard Test Method for Determination of Iodine Number of Activated Carbon" standard. Even though gas adsorption methods are the most commonly used for specific surface area determination, the resulting BET specific surface value has a good correlation with the iodometric titration results, as well [21]. Thus, latter was used for the determination of specific surface area. The particle size distributions of the crushed and ground 
samples were determined with a Horiba LA 950-V2 laser diffraction particle size analyzer, and these samples were observed with a Hitachi TM 1000 scanning electron microscope (SEM).

\section{Results}

During pyrolysis, the $<1 \mathrm{~cm}$ base material loosely filled in the reactor is vitrified, and a loose-textured porous solid residue remains in the reactor. A piece of coke after an experiment $\left(C R B P-725^{\circ} \mathrm{C}\right)$ can be seen in Figure 2. The amount of solid residues and their carbon content after pyrolysis can be seen in Table 2.

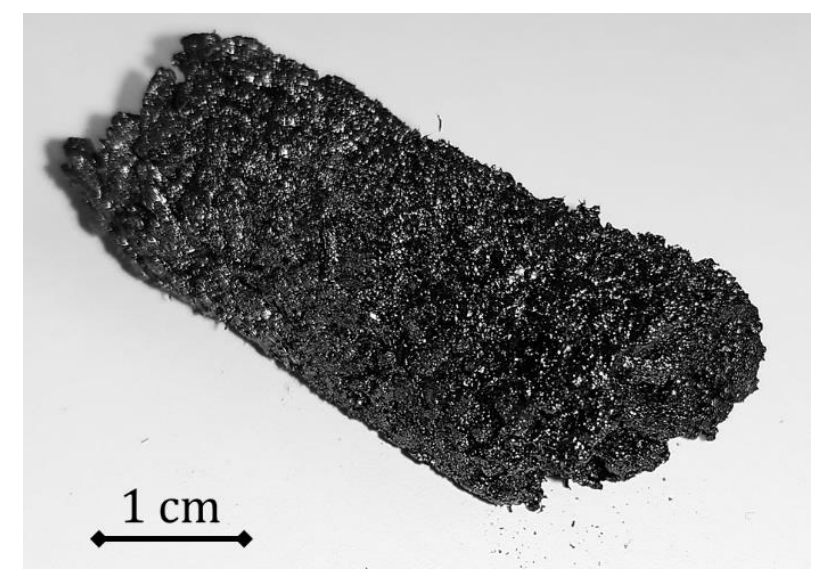

Figure 2. Charred residue of $C R B P-725^{\circ} \mathrm{C}$.

\begin{tabular}{|c|c|c|c|}
\hline Base material & $\begin{array}{c}\text { Temperature of } \\
\text { pyrolysis, }{ }^{\circ} \mathrm{C}\end{array}$ & $\begin{array}{c}\text { Solid residue, } \\
\text { wt.\% }\end{array}$ & $\begin{array}{c}\text { Carbon content of } \\
\text { solid residue, wt.\% }\end{array}$ \\
\hline \multirow{3}{*}{ CRFF } & 900 & 8.8 & 84.79 \\
\cline { 2 - 4 } & 725 & 11.6 & 81.31 \\
\cline { 2 - 4 } & 650 & 21.2 & 69.01 \\
\hline \multirow{3}{*}{ CRBP } & 900 & 8.0 & 81.10 \\
\cline { 2 - 4 } & 725 & 9.0 & 80.04 \\
\hline \multirow{3}{*}{ BPRC } & 650 & 15.2 & 60.66 \\
\cline { 2 - 4 } & 900 & 8.5 & 70.11 \\
\cline { 2 - 4 } & 725 & 10.1 & 69.22 \\
\hline
\end{tabular}

Table 2. Amount of solid residues and their carbon contents.

According to the data of Table 2, as the maximum temperature of pyrolysis is increasing, the amount of coke is decreasing. In parallel, the carbon content of samples is decreasing because as temperature increase, more gas is released from the base material. The carbon content of cokes was 60-85 wt.\%, therefore, these cokes can be a good base material to use as activated carbon. 


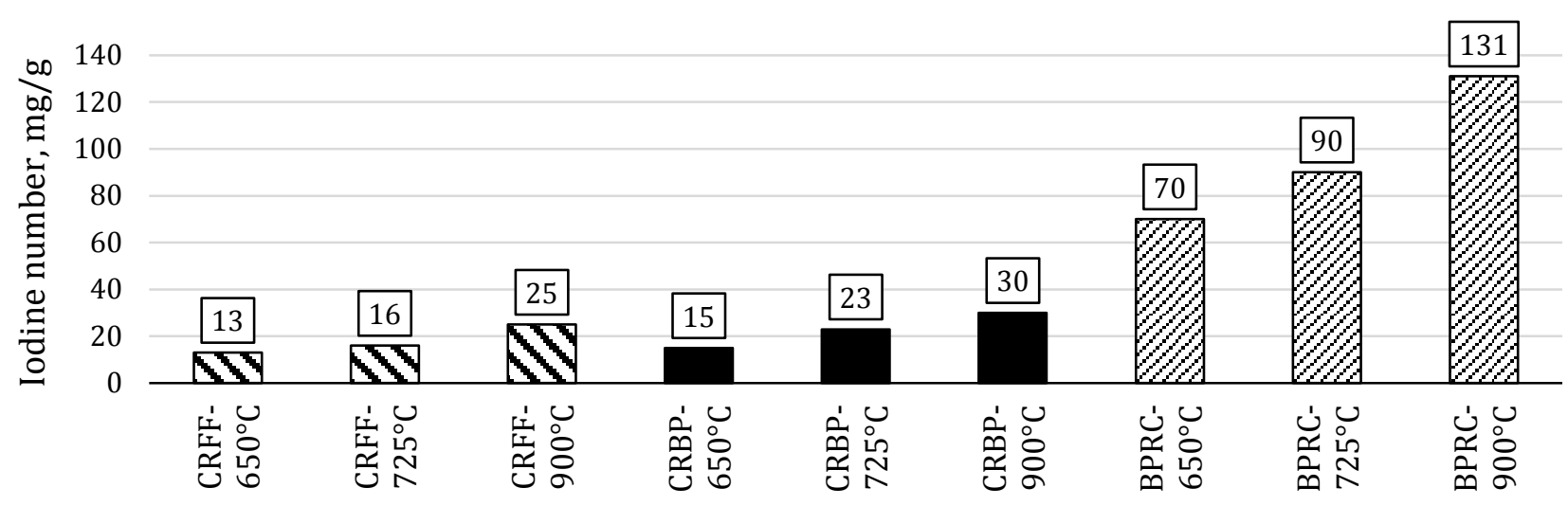

Figure 3. Iodine number of solid residues from pyrolysis at different temperatures.

It can be observed for all three base materials (Figure 3.), that as the temperature increased, the iodine number increased, as well. CRFF and CRBP samples resulted in cokes with small iodine number (1530 ) at all pyrolysis temperatures. Coke with much larger iodine number can be produced from the pyrolysis of mixture which contains only food of animal origin $(B P R C)$.

As plant and animal origin catering wastes are not separated in practice, the CRBP mixture was used for the further milling experiments. Figure 4. shows the change in iodine number as a function of the milling time. The behaviour of cokes from all three pyrolysis experiments was similar. 5-minutes grinding resulted in a slightly increased iodine number, however, an additional 5-minute grinding resulted in a 6-11-fold increase in iodine number, compared to the 5-minutes ground samples. The highest iodine number was measured for the coke of $900^{\circ} \mathrm{C}$ pyrolysis. After 15 -minutes grinding, the iodine number decreased in all cases compared to the 10-minutes grinding.

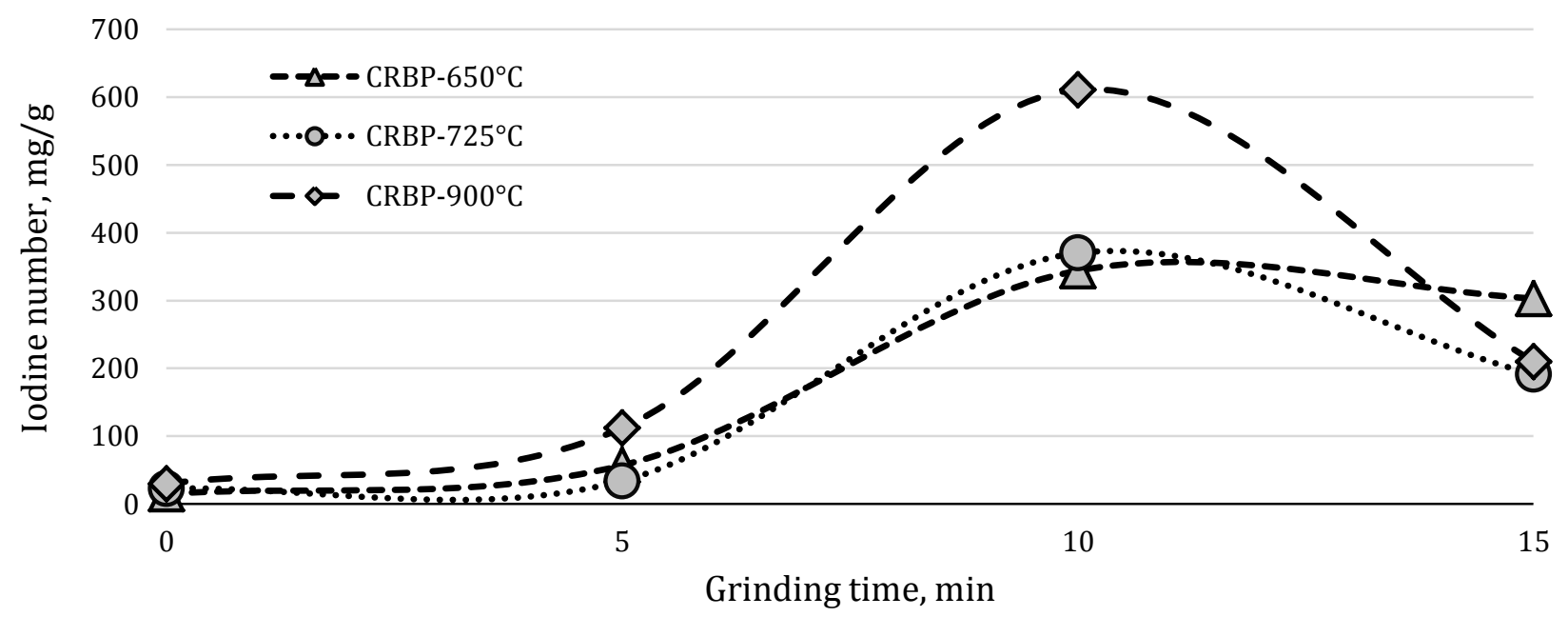

Figure 4. The dependence of iodine number from grinding time.

In order to obtain further information on the decrease in iodine number after 15 minutes of grinding, SEM images were taken, and particle size analyses were performed. The SEM micrographs of samples can be seen in Figure 5.

In the micrograph of crushed $C R B P-900^{\circ} \mathrm{C}$ sample (Figure 5/a) the surface of particles is contiguous, smooth and slightly porous. Large, smooth cavities are visible on the fracture surface. These were 
formed by released volatiles in the softened material during pyrolysis. The fracture surface of the crushed sample clearly shows a brittle-type fracture, which is more observable on the micrographs of the 5-minutes ground sample (Figure 5/b). During grinding, the particle size decreased, and fragmentation occurred mainly along pores and cavities. As a result, flat angular particles were formed. After another 5-minutes grinding (Figure 5/c) smaller amounts of larger particles are visible, and the shape of the particles is similar to the 5-minutes ground samples. In addition, agglomeration can be observed at 1500x magnification on some larger particles. On the SEM images of 15-minutes ground samples (Figure 5/d), a slight decrease in particle size and an increase in the agglomeration of the finer particles can be observed. 
International Journal of Engineering and Management Sciences (IJEMS) Vol. 4. (2019). No. 4

DOI: 10.21791/IJEMS.2019.4.18.

a)
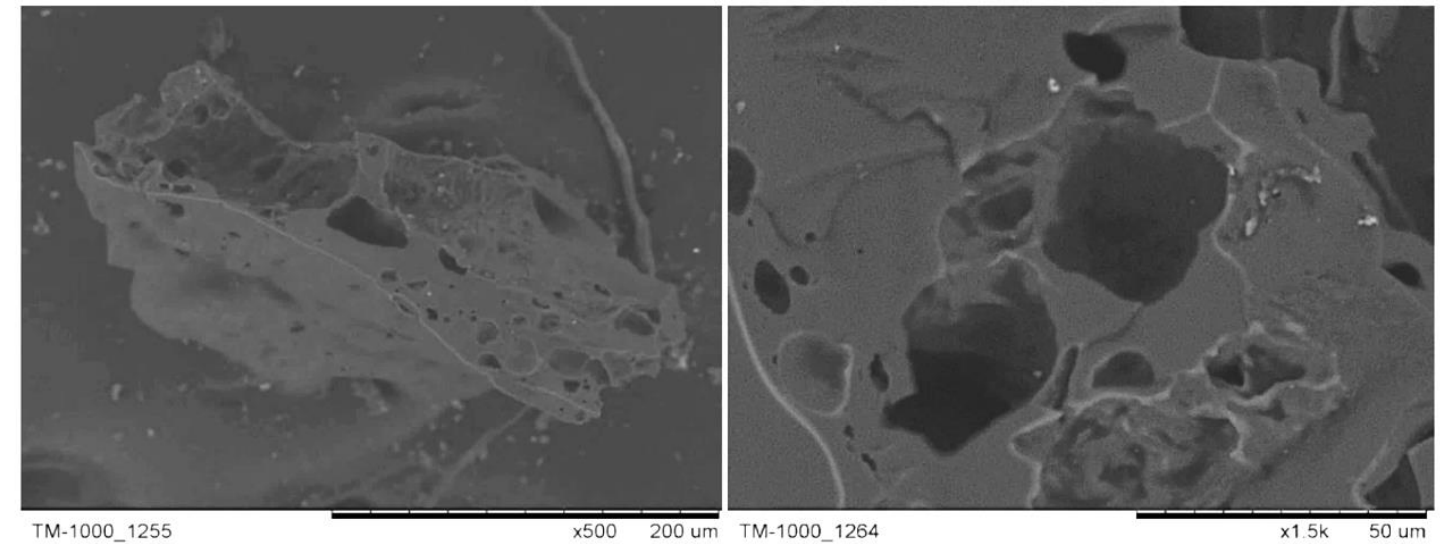

b)
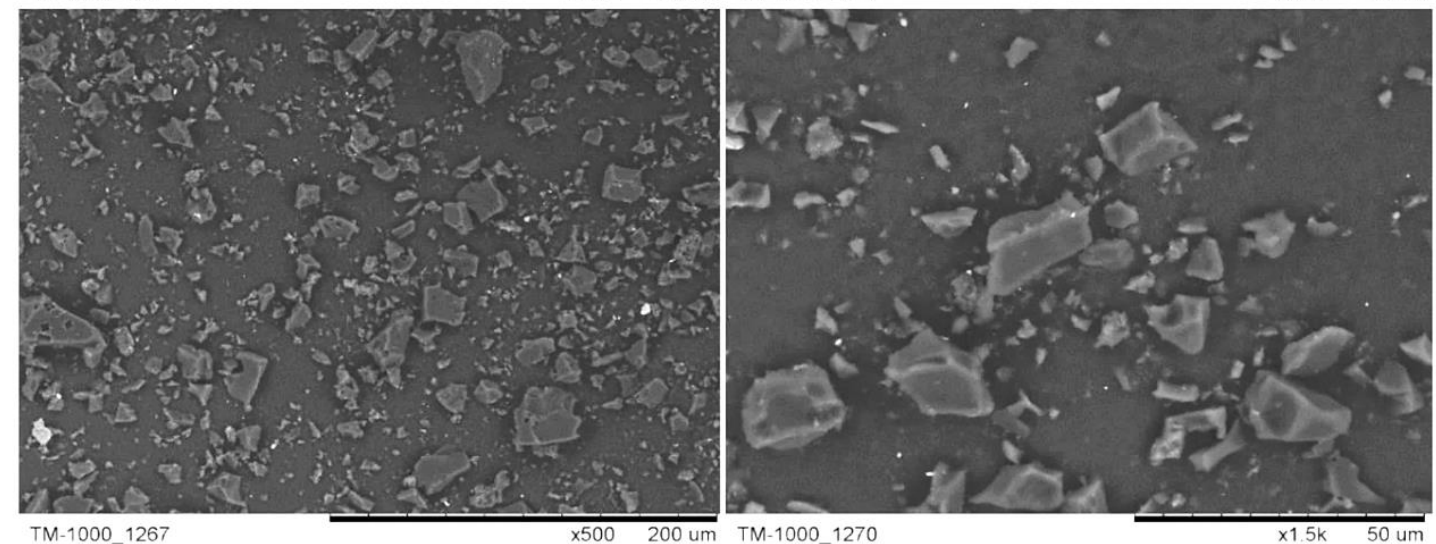

c)
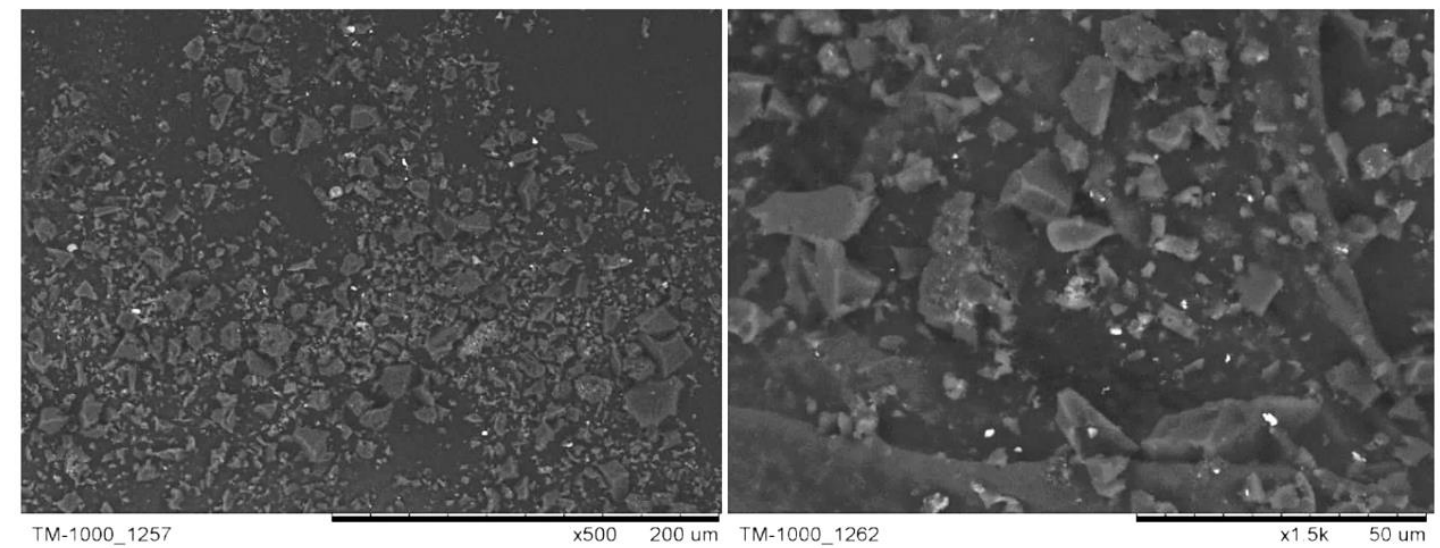

d)
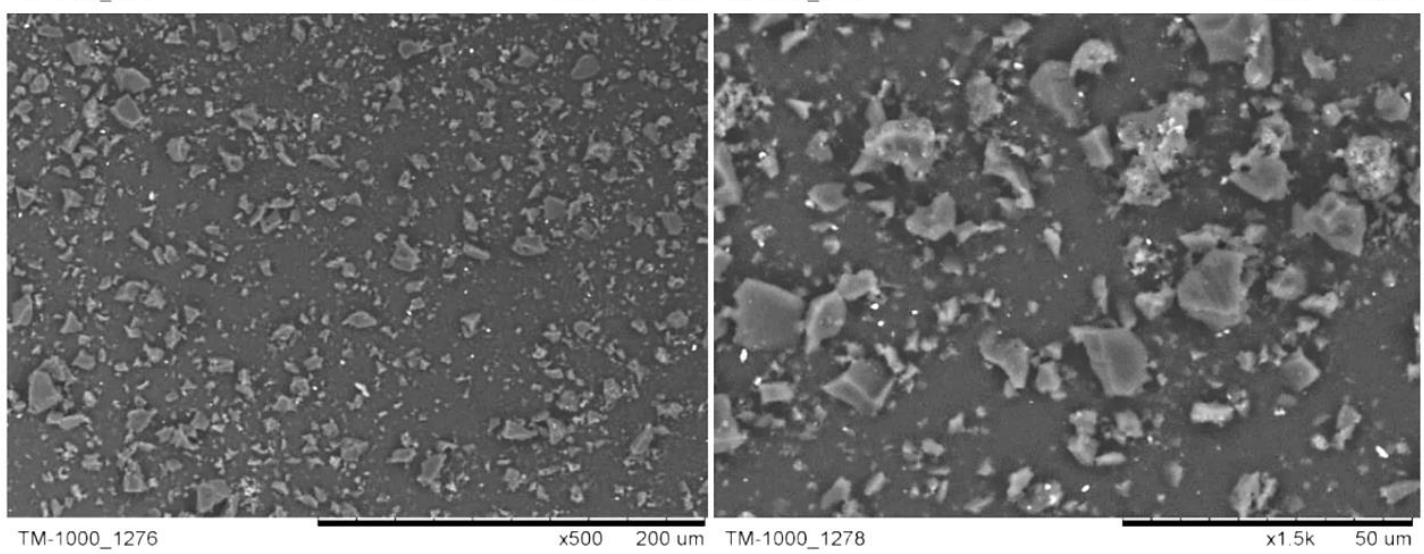

Figure 5. SEM micrographs of crushed (a) and ground CRBP-900 ${ }^{\circ} \mathrm{C}$ sample after $5 \mathrm{~min}(\mathrm{~b}), 10 \mathrm{~min}$ (c) and $15 \mathrm{~min}(\mathrm{~d})$ at 500x and 1500x magnification. 
The characteristic particle sizes of the ground $C R B P-900^{\circ} \mathrm{C}$ samples are summarized in Table 3 .

\begin{tabular}{|c|c|c|c|c|}
\hline $\begin{array}{c}\text { Characteristic } \\
\text { particle size }\end{array}$ & Crushed coke & $\begin{array}{c}\text { After } 5 \text { min } \\
\text { grinding }\end{array}$ & $\begin{array}{c}\text { After } 10 \text { min } \\
\text { grinding }\end{array}$ & $\begin{array}{c}\text { After } 15 \text { min } \\
\text { grinding }\end{array}$ \\
\hline $\mathrm{X}_{10}, \mu \mathrm{m}$ & 39 & 5 & 5 & 4 \\
\hline $\mathrm{X}_{50}$ (median size), $\mu \mathrm{m}$ & 188 & 11 & 8 & 7 \\
\hline $\mathrm{X}_{90}, \mu \mathrm{m}$ & 761 & 22 & 13 & 11 \\
\hline
\end{tabular}

Table 3. Characteristic particle sizes of the crushed and ground coke of CRBP-900 ${ }^{\circ} \mathrm{C}$ samples.

According to the particle size analysis, the characteristic particle sizes $\left(\mathrm{X}_{10}, \mathrm{X}_{50}\right.$ and $\left.\mathrm{X}_{90}\right)$ of the samples decreased in relation to increased grinding time. Thus, the drastic decrease of specific surface cannot be explained with the agglomeration of particles due to the longer grinding time. However, as there was no significant decrease in the particle size after 10- and 15-minutes grinding, the completion of size reduction can be assumed, which could explain the turning point in the specific surface values [22].

\section{Conclusion}

Different catering wastes were pyrolysed at 650,725 and $900{ }^{\circ} \mathrm{C}$, and the suitability of the solid residues as activated carbon was examined.

The resulting 60-85 wt.\% carbon content can provide a good basis for activated carbon production, but the iodine number (therefore the specific surface area) of the crushed samples were small. The particle size was significantly decreased by 5 -minutes grinding, but the iodine number only slightly increased. However, 10-minutes grinding had remarkable effect on the iodine number, but no significant decrease was observed in the particle size. After 15-minutes grinding, the fragmentation was not notable, but based on the SEM images, the agglomeration of the finer particles intensified. Because of this, the iodine number was decreased.

Overall, the cokes had small specific surface area and the SEM images showed slight porosity even in case of crushed cokes, therefore these cokes are considered charred intermediate products rather than activated carbon. Further chemical or physical activation processes are required to achieve the proper structure. Moreover, the optimisation of grinding time is necessary to find the turning point, at which grinding has negative effect on the specific surface area.

\section{Acknowledgement}

The described article was carried out as part of the EFOP-3.6.1-16-2016-00011 "Younger and Renewing University - Innovative Knowledge City - institutional development of the University of Miskolc aiming at intelligent specialisation" project implemented in the framework of the Szechenyi 2020 program. The realization of this project is supported by the European Union, co-financed by the European Social Fund.

The authors are grateful to Mária Ambrus for her linguistic advice. 


\section{References}

[1] E. P. Leimkuehler (2010) Production, Characterization, and Applications of Activated Carbon. Master of Science, Faculty of the Graduate School, University of Missouri, Columbia.

[2] M. Danish - T. Ahmad (2018) A review on utilization of wood biomass as a sustainable precursor for activated carbon production and application. Renewable \& Sustainable Energy Reviews 87 pp. $1-21$.

[3] Council Regulation (EC) No 649/2008 of 8 July 2008 imposing a definitive anti-dumping duty on imports of powdered activated carbon originating in the People's Republic of China, 2008.

[4] ASTM D5158 - 98(2013): Standard Test Method for Determination of Particle Size of Powdered Activated Carbon by Air Jet Sieving, 2013.

[5] F. Scala - R. Chirone - A. Lancia (2011) Elemental mercury vapor capture by powdered activated carbon in a fluidized bed reactor. Fuel 90 (6) pp. 2077-2082.

[6] F. Meinel - F. Zietzschmann - A. S. Ruhl - A. Sperlich - M. Jekel (2016) The benefits of powdered activated carbon recirculation for micropollutant removal in advanced wastewater treatment. Water Research 91 pp. 97-103.

[7] Q. L. He - L. Zhong - H. Y. Wang - Z. C. Zou - D. Chen - K. Yang (2016) Odor removal by powdered activated carbon (PAC) in low turbidity drinking water. Water Supply 16 (4) pp. 1017-1023.

[8] Y. Y. Cui - G. H. Yang - G. H. Xiao - J. H. Zhou - G. Z. Ding - X. J. Pan (2017) Adsorption of Dioxin by Bag Filter plus Powdered Activated Carbon. Water Air Soil Pollution 228 (4), Art no. 160.

[9] C. Priefer - J. Jörissen - K.-R. Bräutigam (2013) Technology options for feeding 10 billion people Options for Cutting Food Waste. Science and Technology Options Assessment, Brussel.

[10] J. C. Buzby - H. F. Wells - J. Hyman (2014) The Estimated Amount, Value, and Calories of Postharvest Food Losses at the Retail and Consumer Levels in the United States. United States Department of Agriculture - Economic Information Bulletin. [Online] http://www.endhunger.org/PDFs/2014/USDA-FoodLoss-2014.pdf (access: 05. 09. 2019.)

[11] Barilla Center for Food \&. Nutrition (2012) Food waste: causes, impacts and proposals. Parma.

[12] Commission Regulation (EU) No 142/2011 of 25 February 2011 implementing Regulation (EC) No 1069/2009 of the European Parliament and of the Council laying down health rules as regards animal by-products and derived products not intended for human consumption and implementing Council Directive 97/78/EC as regards certain samples and items exempt from veterinary checks at the border under that Directive Text with EEA relevance.

[13] G. Nagy - Á. Wopera - T. Koós (2019) The Lab-scale and Thermogravimetric Analysis of the Catalytic and Non-catalytic Co-pyrolysis of Oak and Canteen Waste Mixture. International Journal of Environment and Waste Management. in press.

[14] G. Nagy - Á. Wopera - T. Koós - R. Szabo (2018) The pyrolysis of canteen waste and oak mixtures in various ratios. Energy Sources, Part A-Recovery Utilization, and Environmental Effects. 40 (18) pp. 2124-2136.

[15] T. Krithiga - X. J. Sabrina - B. Rajesh - H. Ilbeygi - A. N. Shetty - R. Reddy - J. Karthikeyan (2018) Cooked Food Waste-An Efficient and Less Expensive Precursor for the Generation of Activated Carbon. Journal of Nanoscience and Nanotechnology. 18 (6) pp. 4106-4113.

[16] R. I. Kosheleva - A. C. Mitropoulos - G. Z. Kyzas (2019) Synthesis of activated carbon from food waste. Environmental Chemistry Letters. 17 (1) pp. 429-438. 
[17] G. Z. Kyzas - E. A. Deliyanni - K. A. Matis (2016) Activated carbons produced by pyrolysis of waste potato peels: Cobalt ions removal by adsorption. Colloid Surfaces A: Physicochemical Engineering Aspects. 490 pp. 74-83.

[18] M. E. Fernandez - G. V. Nunell - P. R. Bonelli - A. L. Cukierman (2014) Activated carbon developed from orange peels: Batch and dynamic competitive adsorption of basic dyes. Industrial Crops and Products. 62 pp. 437-445.

[19] M. Louarrat - G. Enaime - A. Bacaoui - A. Yaacoubi - J. Blin - L. Martin (2019) Optimization of conditions for the preparation of activated carbon from olive stones for application in gold recovery. Journal of the Southern African Institute of Mining and Metallurgy. 119 (3) pp. 297306.

[20] D. L. Klass, Biomass for Renewable Energy, Fuels, and Chemicals. Elsevier Inc., 1998.

[21] A. Mianowski - M. Owczarek - A. Marecka (2007) Surface area of activated carbon determined by the iodine adsorption number.," (in English), Energy Sources, Part A-Recovery Utilization, and Environmental Effects. 29 (9) pp. 839-850.

[22] C.-X. Chen - B. Huang - T. L. Li - G.-F. Wu (2012) Preparation of phosphoric acid activated carbon from sugarcane bagasse by mechanochemical processing. Bioresources. 7 (4) pp. 5109-5116. 